\title{
Past sea ice reconstruction - proxy data and modeling
}

\author{
Rainer Gersonde', A. de Vernal ${ }^{2}$ and E. W. Wolff ${ }^{3}$ \\ $3^{\text {rd }}$ Sea Ice Proxies (SIP) Working Group workshop - Bremerhaven, Germany 23-25 July 2014
}

\begin{abstract}
The distinct contrast between recent trends in Arctic and Antarctic sea ice calls for sea ice records extending beyond instrumental observations. Such estimates must rely on well-established sea ice proxy data obtained from marine, ice core and coastal materials and should ideally be supported by sea ice modeling.
\end{abstract}

A primary goal of the PAGES Sea Ice Proxies (SIP) Working Group is to critically assess different sea ice proxies. This issue was central to the first SIP workshop in 2012 and resulted in the publication of 18 papers. Further proxy development, comparisons and applications in time-series and time-slice reconstructions were stimulated and discussed at the second SIP workshop in 2013.

The third workshop focused on sea ice data syntheses, sea ice modeling and proxy-data/ model comparisons. In addition, recent progress in proxy development was presented, such as a new proxy using crustose coralline algae to extend the instrumental observations of Arctic sea ice at annual resolution (Halfar et al. 2013). Recent identification of the source of the biomarker IP $\mathrm{P}_{25}$ makes it a more powerful proxy for Arctic sea ice (Brown et al. 2014). Antarctic sea ice estimates are primarily based on diatom records (e.g. Esper and Gersonde 2014) because the establishment of biomarkers as robust proxies for Antarctic sea ice still requires more study. Strong efforts to better understand aerosols (sea salt, halogens, methanesulfonic acid) and their production mechanisms, transport and deposition have enhanced their applicability as sea ice proxies in ice cores (e.g. Levine et al. 2014). While the limitations, strengths and significance of individual proxies can be tested through proxy intercomparison (Fig. 1), a deeper understanding requires more joint projects between paleoclimatologists, and biologists and physicists studying modern sea ice processes. Additionally, the development of new proxies (e.g. DNA-based identification of foraminifers living in sea ice) should be intensified.

Arctic sea ice development in the Holocene at 2000 year time slices was presented.

Time-series studies from different sectors of the northern polar realm since the last glacial document the complex pattern of sea ice variability, and allow us to better evaluate sea ice/climate feedbacks during the last
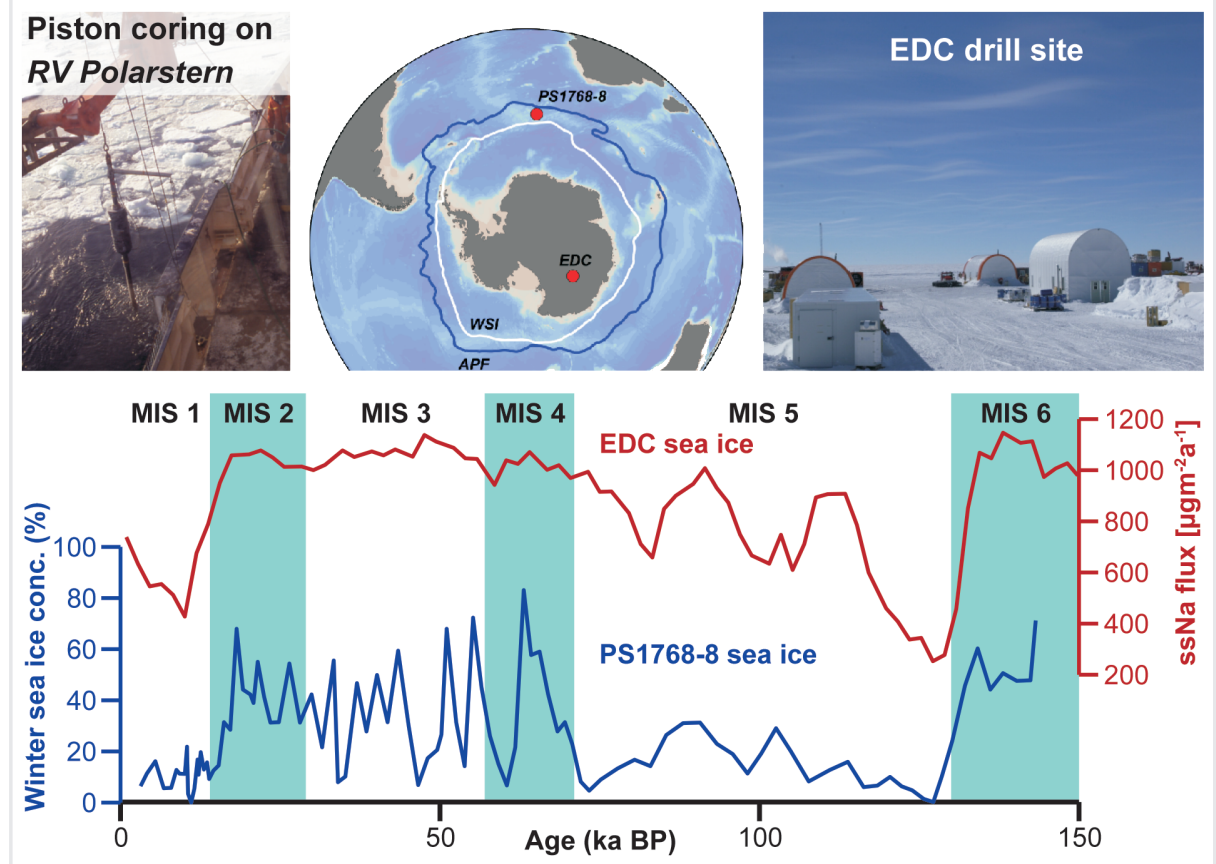

Figure 1: Comparison of marine (PS1768-8) and ice core (EDC) records documenting Antarctic sea ice variability during the last climate cycle. In the middle top panel, the location of the EDC and the marine core are presented relative to the modern average winter sea ice extent (WSI, at $40 \%$ concentration) and the Antarctic Polar Front (APF). The records show concurring sea ice minima during the Marine Isotope Stages (MIS) 5 and 1, and similar sea ice retreat during the glacial/interglacial transitions. The marine record displays strong variability during MIS 2-4, while the ice core record shows a more stable signal. Data from Esper and Gersonde 2014 and Wolff et al. 2006. glacial-interglacial transition. Similar data, but at lower resolution, were also presented from the Pacific and Atlantic sectors of the Southern Ocean. This provides a picture of bipolar sea ice variability under natural conditions giving a context for modern changes. Antarctic sea ice data have also been developed for the penultimate glacial-interglacial transition and the last interglacial, which may represent conditions that could develop in a future warmer-climate state.

The participants concluded that robust sea ice estimates with large spatial coverage under a broad range of climate conditions should rely on a combination of different proxies according to their specific applicability. Model-data comparisons perform best when there is an abundance of data for assimilation. Data gaps in spatial and seasonal information may be bridged by sea ice modeling. However, such modeling needs further improvement as there remain uncertainties possibly related to sea ice parameterization and applied boundary conditions. The development of bipolar sea ice syntheses for the last two glacial-interglacial transitions and subsequent interglacials presents a crucial step towards improved integration of sea ice as a polar amplification and feedback factor, which is important for more robust projections of future conditions. SIP3 encourages the increased integration and comparison of data and modeling results to improve future paleoclimate research. Although this was the last PAGES-sponsored SIP meeting, SIP intends to continue with sessions at major meetings (e.g. as scheduled at AGU Fall 2014 and INQUA 2015) and through mailings between the participants. To join the SIP mailing list, visit https://listserv.unibe.ch/mailman/listinfo/seaice.pages

\section{AFFILIATIONS}

'Alfred-Wegener-Institute Helmholtz Centre for Polar and Marine Research, Bremerhaven, Germany

${ }^{2}$ GEOTOP, Université du Québec à Montréal, Canada

${ }^{3}$ Department of Earth Sciences, University of Cambridge, UK

\section{CONTACT}

Rainer Gersonde: Rainer.Gersonde@awi.de

REFERENCES

Brown TA et al. (2014) Nat Commun 5, doi: 10.1038/ ncomms5197

Esper O, Gersonde R (2014) Palaeogeog Palaeoclimatol Palaeoecol 399: 260-283

Halfar J et al. (2013) PNAS 110: 19737-19741

Levine JG et al. (2014) J Geophys Res Atmos 119: 5737-5756

WolffEW et al. (2006) Nature 440: 491-469 